\title{
MANAJEMEN PROGRAM PENDIDIKAN KEAGAMAAN KE-NAHDLATUL ULAMA-AN DI SMA NAHDLATUL ULAMA LEKOK PASURUAN
}

\author{
Zumrotun Nafisah ${ }^{1}$, Siti Aminah ${ }^{2}$ \\ ${ }^{1}$ IAIN Jember, Jl. Mataram No.1 Mangli Jember, Jawa Timur Indonesia \\ e-mail: nafiszumrotun24@gmail.com \\ ${ }^{2}$ IAIN Jember, Jl. Mataram No.1 Mangli Jember, Jawa Timur Indonesia \\ e-mail: siti.aminaprayoga@gmail.com
}

DOI: 10.35719/leaderia.v2i1.55

\begin{abstract}
The Nahdlatul Ulama senior high school of Lekok, Pasuruan, is an education institution under the Nahdlatul Ulama whose religious education programs are based on the values of ahlussunah wal jamaah (Aswaja). The purpose of this study is to know the planning, organization, performance and evaluation of the religious education program about NU. The researcher went directly to the study using observation methods, interviews and documentation. The research findings are 1) the planning of religious educational activities program is carried out by viewing future needs, setting goals based on madrassa's mission vision, determining policies, by little cost and each activity has its own time to implement. 2) the organization of the religious activity program is carried out by performing what type of duty and responsibility identification based on each individual's abilities and qualifications. Continued by assessing the nature of the task and responsibility, determining and distributing the task and responsibility 3) executing this program of NU's religious activities consists of a) praying dhuha and reading the surah al-Waqiah and continuing with the book study being done daily by jamaah, b) praying dhuhur, which is ended by reading the surah al-Mulk and Asmaul Husna and administered daily, C) the madrasah program executed after the learning activity for students who do not follow the religious madrassa activity, d) reading the tahlil through a memorization system carried out each week, 4) the evaluation of the NU activities program is carried out each week by bringing small notes related to the activities being done in order to fit the plans.
\end{abstract}

Keywords: Religious Education Program Management, Nahdlatul Ulama

\begin{abstract}
ABSTRAK
Lembaga pendidikan SMA NU Lekok Pasuruan merupakan lembaga pendidikan di bawah naungan Nahdlatul Ulama yang memiliki program pendidikan keagamaan ke$N U$-an yang berlandaskan nilai-nilai Ahlussunah Wal Jamaah (Aswaja). Tujuan penelitian ini untuk mengetahui perencanaan, pengorganisasian, pelaksanaan dan evaluasi program pendidikan keagamaan ke-NU-an, penulis melakukan langsung ke tempat penelitian dengan menggunakan metode observasi, wawancara dan dokumentasi. Hasil penelitian yaitu 1) Perencanaan program kegiatan pendidikan
\end{abstract}


keagamaan NU ini dilaksanakan dengan melihat kebutuhan masa depan, menetapkan tujuan yang berdasarkan pada visi misi madrasah, menentukan kebijakan, dengan sedikit biaya dan setiap kegiatan mempunyai waktu pelaksanaan masing-masing. 2) Pengorganisasian program kegiatan keagamaan $N U$ ini dilaksanakan dengan melakukan identifikasi jenis tugas dan tanggung jawab berdasarkan kemampuan masing-masing individu disertai kualifikasi ijazah. Dilanjutkan dengan menggolongkan jenis tugas dan tanggung jawab, menentukan dan mendistribusikan tugas dan tanggung jawab 3) Pelaksanaan program kegiatan keagamaan NU ini terdiri dari a)sholat dhuha berjamaah dan membaca Surat al-Waqiah dan dilanjutkan dengan kajian kitab dilaksanakan setiap hari secara berjamaah, $b$ ) sholat dhuhur berjamaah yang diakhiri dengan membaca Surat al-Mulk dan Asmaul Husna dan dilaksanakan setiap hari, c) Program Madrasah Diniyah yang dilaksanakan usai kegiatan belajar bagi siswa yang tidak mengikuti Madin, d) membaca Tahlil melalui sistem setor hafalan yang dilaksanakan setiap minggu, 4) Evaluasi program kegiatan kegamaan $N U$ ini dilaksanakan setiap minggu sekali dengan membawa catatan-catatan kecil terkait dengan kegiatan yang dilaksanakan agar sesuai dengan yang direncanakan.

KataKunci: Manajemen Program Pendidikan, Keagamaan NU

\section{PENDAHULUAN}

Keagamaan merupakan sesuatu yang berhubungan dengan agama, agama adalah keseluruhan tingkah laku manusia yang terpuji, yang dilakukan demi memperoleh ridha Allah. Dalam lembaga pendidikan NU ada materi pendidikan yang menjadi ciri khas atau corak yang tidak boleh tidak ada yaitu Ahlussunah Wal Jamaah (Aswaja). Ahlussunnah Wal Jamaah (Aswaja) adalah nama bagi golongan yang selalu mengikuti perilaku sunnah Nabi dan para sahabatnya. Aswaja merupakan golongan pengikut ajaran Islam yang dilakukan oleh Nabi Muhammad SAW dan para sahabatnya. Aswaja adalah golongan yang masuk dari katagori hadis Nabi Maa ana 'Alaihi wa Ash-Haabi yang artinya "apa yang aku berada di atasnya bersama sahabatku" yang artinya golongan aswaja adalah golongan yang mengikuti ajaran Islam sebagaiman diajarkan dan diamalkan Rosulullah beserta sahabatnya. Sesuai dengan hadis nabi yaitu:

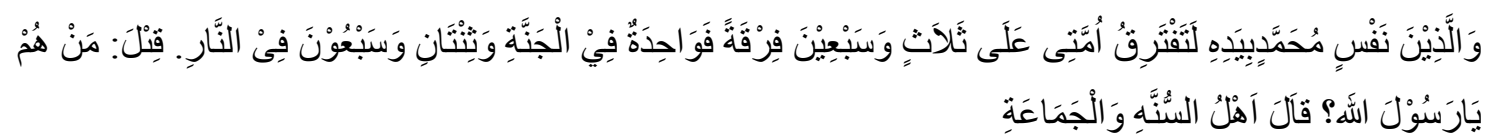

Artinya: "Demi tuhan yang memegang jiwa muhammad di tangannya, akan berfirqoh ummatku sebanyak 73 firqoh yang satu masuk surga dan yang lain masuk neraka” bertanya nama sahabat: "siapakah firqoh yang tidak masuk neraka itu ya rosulullah". Nabi menjawab: "Ahlussunah Wal Jamaah".

Nabi Muhammad telah mengisyaratkan bahwa ummatnya akan terpecah menjadi 73 golongan. Semuanya celaka kecuali satu yang selamat, yaitu golongan Ahlussunah Wal Jamaah. 
Tentu saja semua umat Islam ingin masuk golongan yang selamat itu. Meski yang tidak selamat pun masih termasuk umat Islam, umat Muhammad. Dalam lembaga pendidikan NU tidak lepas dari penanaman nilai-nilai Aswaja yaitu aqidah, syari'ah dan ahklaq. Dari ketiga tersebut merupakan satu kesatuan ajaran yang mencangkup seluruh aspek prinsip keagamaan. Lembaga pendidikan yang menyandang nama Nahdlatul Ulama merupakan lembaga pendidikan yang menekankan pada aspek agama atau ritual Aswaja. Aswaja adalah pengikut ajaran islam yang berlandaskan pada AlQur'anul Karim, Sunnah (perkataan, perbuatan dan taqrir) Nabi Muhammd SAW sebagaimana telah dilakukan bersama para sahabatnya, dan sunnah Khalafaur rasyidin.

Sesuai dengan ayat dalam Al-Qur'an surat An-Nisa' ayat 59:

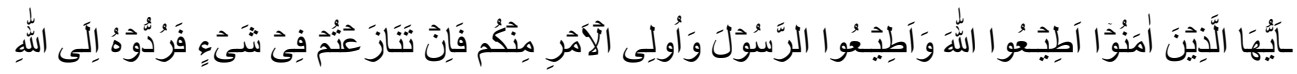

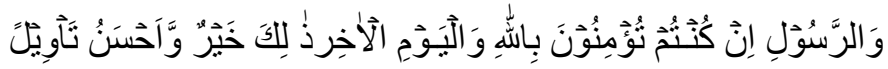

Artinya: "Hai orang-orang yang beriman, taatilah Allah dan taatilah Rasul (Nya), dan ulil amri di antara kaтu. kemudian jika kamu berlainan Pendapat tentang sesuatu, Maka kembalikanlah ia kepada Allah (Al Quran) dan Rasul (sunnahnya), jika kamu benarbenar beriman kepada Allah dan hari kemudian. yang demikian itu lebih utama (bagimu) dan lebih baik akibatnya".

Dari penggalan ayat di atas bahwa kembalikan persoalan kepada Allah, berarti mengembalikannya kepada Al-Qur'an, sedangkan mengembalikan persoalan kepada rosul berarti mengembalikannya kepada sunnah rosul yang shohiholongan yang mengaku sebagai golongan Aswaja.

Ada beberapa kajian terdahulu yang revelan dengan penelitian ini. Pertama, Laela Fitriani meneliti (2017) implementasi Pembelajaran Aswaja dan ke-NU-an dalam Menanamkan Nilai-nilai Keagamaan di SD Darus Sholah Jember. Kedua, Ibniyanto (2017) meneliti Implementasi Pembelajaran Aswaja dalam Pembentukan Perilaku Sosial dan Keagamaan Peserta Didik di SMA Pesantren Al-In'am Gapura Sumenep. Ketiga, Trians Yanuarti (2018) meneliti Pembelajaran Aswaja pada Kelas Intensive di SMA Ma'arif Kroya.

Jadi, perbedaan penelitian terdahulu yang telah diuraikan di atas dengan penelitian ini terletak pada lokasi penelitian dan konteks yang diteliti. Dalam penelitian ini, fokusnya tentang manajemen program pendidikan keagamaan ke-NU-an di Madrasah Aliyah Nahdlatul Ulama Lekok Pasuruan. Manajemen program pendidikan keagamaan NU yang dimaksud adalah bagaimana proses perencanaan, pengorganisasian, pelaksanaan, dan evaluasi program pendidikan keagamaan ke-NU-an. 
Sedangkan manfaat yang diharapkan dari penelitian ini ada dua yaitu: pertama, manfaat teoritis dan kedua manfaat praktis. Manfaat teoritis dari penelitian ini yaitu 1) menambah khazanah keilmuan terkait pendidikan keagamaan NU bagi masyarakat sebagai bekal di masa depan; 2) hasil penelitian ini dapat menjadi refrensi bagi peneliti berikutnya dengan tema sejenis dalam rangka mengembangkan manajemen pendidikan dengan nilai-nilai keislaman. Adapun manfaat praktis dari penelitian ini yaitu: 1) bagi peneliti, untuk menambah wawasan dan pengalaman dalam melaksanakan penelitian yang berkaitan dengan manajemen program pendidikan keagamaan, 2) bagi lembaga (IAIN Jember) diharapkan penelitian ini menjadi refrensi dan informasi dalam rangka menciptakan dan mengembangkan dinamika budaya intelektual masyarakat kampus, 3) bagi Madrasah Aliyah Nahdlatul Ulama diharapkan penelitian ini sebagai refrensi terkait manajemen program pendidikan keagamaan NU.

\section{METODE}

Penelitian ini menggunakan pendekatan penelitian kualitatif deskriptif. Karena dalam penelitian ini lebih menekankan pada makna, gambaran, keadaan dan proses dari pada hasil dari aktivitas. Sehingga data yang diperoleh dari penulis dapat dideskripsikan dengan obyektif sesuai dengan kenyataan yang terdapat di lapangan. Jenis penelitian yang dilakukan ialah penelitian studi kasus. Subyek yang ditetapkan sebagai informan dalam penelitian ini adalah kepala madrasah, Waka Kesiswaan, Waka Kurikulum, Guru dan ketua IPNU.

Teknik pengumpulan data yang digunakan yaitu: 1) observasi non partisipan, 2) wawancara semi terstruuktur, dan 3) dokumentasi. Analisis data yang digunakan sebagai berikut: 1) kondensasi data meliputi seleksi data, peringkasan, penyederhanaan transformasi, 2) penyajian data yaitu sebuah penyatu dari informan yang memungkinkan penyimpulan data aksi, 3) penarikan kesimpulan yaitu penyimpulan data sesuai dengan rumusan masalah yang telah dikemukakan.

\section{HASIL DAN PEMBAHASAN}

Temuan penelitian merupakan penafsiran dan penjelasan dari temuan yang diungkap dari lapangan mengenai "Manajemen Program Pendidikan Keagamaan Nahdlatul Ulama (NU)" untuk itu pembahasan ini akan disesuaikan dengan sub yang menjadi pokok pembahasan, guna mempermudah dalam menjawab pertanyaan yang menjadi landasan dalam penelitian.

\section{Perencanaan program pendidikan keagamaan ke-Nahdlatul Ulama-an di Madrasah Aliyah Nahdlatul Ulama Lekok Pasuruan.}

Perencanaan merupakan tindakan menetapkan terlebih dahulu apa yang akan dikerjakan, bagaimana mengerjakannya, apa yang harus dikerjakan dan siapa yang mengerjakannya, 
mendatangkan pengajar dari luar atau tidak, agar program yang akan dilaksanakan bisa diterima oleh siswa.

Langkah-langkah perencanaan mempunyai 6 tahap sebagaimana yang dikemukakan oleh St.Rodiyah, yaitu melangkah kedepan dan memprediksi kebutuhan dikemudian hari, menetapkan tujuan, menentukan kebijakan, menyusun program, menyusun biaya, menentukan waktu/jadwal kegiatan. ${ }^{1}$

Setiap kegiatan yang akan dikerjakan secara efektif dan efisien apabila sudah dipersiapkan dan direncanakan dengan matang. Begitu juga untuk merealisasikan program pendidikan keagamaan NU di Madrasah Aliyah Nahdlatul Ulama Lekok Pasuraun, diawali dengan melangkah ke depan untuk memprediksi kebutuhan, menentukan tujuan, menentukan kebijakan, menyusun program, menentukan biaya, dan menyusun waktu /jadwal kegiatan, program pendidikan keagamaan yaitu sholat dhuha, kajian kitab, sholat dhuhur, hingga kegiatan madin dan tahlil yang melangkah ke depan untuk memprediksi kebutuhan kemudian hari dengan usaha pencegahan kelalaian terhapat kewajiban terhapat Allah dengan menanamkan kegiatan-kegiatan keagamaan seperti yang tertera di dokumen. Setelah melangkah ke depan dan memprediksi kebutuhan dikemudian hari kemudian menentukan tujuan seperti yang dikatakan oleh kepala madrasah dan guru Madrasah Aliyah Nahdlatul Ulama Lekok Pasuruan, yaitu untuk menentukan tujuan ini kita melihat visi misi madrasah yaitu berjiwa santri dengan tujuan untuk menanamkan kebiasaan para salafus shaleh kepada diri siswa dan guru dan juga agar anak-anak mempunyai kegiatan-kegiatan yang mencerminkan kehidupan santri dan bisa meneladaninya,

Hal ini sebagaimana teori yang diungkapkan oleh Richard L.Daft, bahwa perencanaan berarti mengidentifikasi berbagai tujuan untuk kinerja organisasi di masa mendatang serta memutuskan tugas dan penggunaan sumber daya yang diperlukan untuk mencapainya. ${ }^{2}$ Setelah menentukan tujuan maka dilakukan kegiatan menentukan kebijakan dengan tujuan agar kegiatan yang dilakukan itu mempunyai aturan yang bisa diterima oleh semua pihak dengan melihat jenis kegiatan yang akan dilaksanakan, setelah menentukan kebijakan maka dilakukan menyusun program kegiatan dengan tujuan agar kegiatan yang dilaksanakan tepat sasaran dan terarah sesuai yang dikatakan oleh kepala madrasah dan guru yang diwawancarai, setelah menyusun program maka dilakukan penentuan biaya agar kegiatan yang banyak membutuhkan budget bisa diketahui sejauh ini kegiatan yang dilaksanakan di Madrasah Aliyah tidak membutuhkan biaya yang banyak sesuai yang dikatakan oleh kepala madrasah dan guru yang diwawancarai, kemudian setelah menentuan biaya maka dilakukan menentukan waktu kegiatan dengan tujuan agar kegiatan yang

\footnotetext{
${ }^{1}$ Siti Rodliyah, Manajemen Pendidikan, 15

${ }^{2}$ Richard L.Daft, Era Baru Manajemen,(Jakarta:Salemba Empat,2010)ed.ke-9,212
} 
dilaksanakan itu sesuai dengan jadwal dan mencapai sasaran yang diinginkan sesuai yang dikatakan oleh kepala madrasah dan guru yang diwawancarai oleh peneliti.

Dari hasil analisis di atas dapat disimpulkan bahwa perencanaan program pendidikan keagamaan NU sudah direncanakan dengan baik dan matang. Setiap program yang akan dilaksanakan melalui musyawarah terlebih dahulu. Perencanaan kegiatan yang akan dilakukan membutuhkan pertimbangan yang banyak agar kegiatan yang akan dilaksanakan bisa berjalan secara efektif dan efisien.

\section{Pengorganisasian Program Pendidikan Keagamaan ke-Nahdlatul Ulama-an di Madrasah} Aliyah Nahdlatul Ulama Lekok Pasuruan

Ada tiga langkah yang diambil manajer dalam pengorganisasian antara lain, mengidentifikasi jenis tugas dan tanggung jawab, menggolongkan jenis tugas dan tanggung jawab, menentukan dan mendistribusikan jenis tugas, dan tanggung jawab. ${ }^{3}$

Pelaksanaan pengorganisasian di Madrasah Aliyah Nahdlatul Ulama dilakukan dengan cara mengidentifikasi jenis tugas dan tanggung jawab, menggolongkan jenis tugas dan tanggung jawab, menentukan dan mendistribusikan jenis tugas, dan tanggung jawab.

Mengidentifikasi jenis tugas dan tanggung jawab program pendidikan keagamaan ke-NUan di Madrasah Aliyah Nahdlatul Ulama, berdasarkan data yang diperoleh melalui wawancara dengan kepala madrasah dan guru, mengidentifikasi jenis tugas dan tanggung jawab ini melihat dari jenis kegiatan yang akan dilimpahkan dengan melihat kemampuan dari pihak yang akan dilimpahkan tugas.

Menggolong-golongkan jenis tugas dan tanggung jawab program pendidikan keagamaan di Madrasah Aliyah Nahdlatul Ulama, berdasarkan data yang diperoleh melalui wawancara dengan kepala madrasah dan guru bahwasanya menggolongkan jenis tugas ini dilihat dari jenis dan waktu pelaksanaaan agar pelaksanaan kegiatan bisa berjalan secara maksimal.

Menentukan dan mendistribusikan tugas dan tanggung jawab program pendidikan keagamaan di Madrasah Aliyah Nahdlatul Ulama, berdasarkan data yang diperoleh melalui wawancara dengan kepala madrasah dan guru behwasannya menentukan dan mendistribusikan tugas kepada pihak yang dilimpahkan tugas dilihat dari kemampuannya, kualifikasi ijazah maupaun dari kepala madrasah sendiri dengan melakukan musyawarah terlebih dahulu dengan tujuan untuk mempermudah pelaksanaan kegiatan agar kegiatan tersebut tidak keteteran dan bisa mencapai target yang sudah ditentukan.

\footnotetext{
${ }^{3}$ Siti Rodliyah, Manajemen Pendidikan, 23
} 
Hal ini sebagaimana teori yang diungkapkan oleh Koontz at.al, bahwa pengorganisasian yang efektif dapat membagi habis (merata) dan menstrukturkan tugas-tugas ke dalam sub-sub komponen organisasi. ${ }^{4}$ Pembagian tugas melalui proses membagi kerja ke dalam tugas-tugas kecil, membebankan tugas-tugas itu kepada orang sesuai dengan kemampuannya, dan mengalokasikan sumber daya, serta mengkoordinasikannya dalam rangka efektifitas pencapaian tujuan organisasi. ${ }^{5}$

Pembagian tugas ini merupakan usaha menciptakan hubungan tugas yang jelas antar personalia, sehingga dengan demikian setiap orang dapat bekerja sama dalam kondisi yang baik untuk mencapai tujuantujuan organisasi.

\section{Pelaksanaan Program Pendidikan Keagamaan ke-Nahdlatul Ulama-an di di Madasah Aliyah Nahdlatul Ulama Lekok Pasuruan}

Actuating merupakan fungsi manajemen yang komplek dan ruang lingkup yang cukup luas serta sangat berhubungan erat dengan sumber daya manusia yang pada akhirnya actuating merupakan pusat sekitar aktifitas-aktifitas manajemen. Pelaksanaan atau actuating pada hakekatnya adalah menggerakkan orang-orang untuk mencapai tujuan yang telah ditetapkan secara efektif dan efisien. ${ }^{6}$

Menggerakkan dalam organisasi sekolah berarti merangsang guru dan personal sekolah lainnya melaksanakan tugas-tugas dengan penuh antusias dan kemauan yang baik untuk mencapai tujuan dengan penuh semangat. ${ }^{7}$ Adapun pelaksanaan program pendidikan keagamaan ke-NU-an di Madrasah Aliyah Nahdlatul Ulama Lekok Pasuruan seperti yang dikatakan oleh kepala madrasah dan guru yang diwawancarai bahwa program pendidikan keagamaan dilaksanakan sebagaimana yang telah dijadwalkan. Program pendidikan keagamaan yang diadakan tentu sudah direncanakan dengan matang. Akan tetapi, masih ada siswa yang tidak atau telat mengikuti kegiatan di pagi hari karena masih mengikuti kegiatan yang dipondoknya, misal dalam kegiatan sholat dhuha yang dijadwalkan setiap pagi, ada beberapa murid yang telah mengikuti sholat dhuha karena masih mengikuti kegiatan yang di dalam pondok oleh karena itu kepala madrasah dan guru sepakat untuk memberikan waktu kepada siswa yang telat untuk mengganti rokaat sholat dhuha yang tertinggal.

\section{Evaluasi Program Pendidikan Keagamaan ke-Nahdlatul Ulama-an di Madasah Aliyah Nahdlatul Ulama Lekok Pasuruan.}

Evaluasi dilakukan untuk melihat kembali apakah program tersebut dilaksanakan sesuai dengan perencanaan dan sesuai dengan tujuan, berdasarkan hasil evaluasi selanjutnya diambil

\footnotetext{
${ }^{4}$ Rodliyah, Manajemen Pendidikan, 20

${ }^{5}$ Fathor Rochman, Manajemen Organisasi dan Pengorganisasian Dalam Perspektif Al-Quran dan Hadith Vol.1, No.2, (Desember, 2015), 294

${ }^{6}$ Sulisyorini, Manajemen Pendidikan Islam: Konsep Strategi dan Aplikasi, (Yogyakarta:TERAS, 2009), 31

${ }^{7}$ Syaiful Sagala, Manajemen Strategik dalam Peningkatan Mutu Pendidikan, (Bandung:Alfabeta,2009), 60
} 
keputusan apakah program akan diteruskan, direvisi, dihentikan karena menimbulkan banyak masalah atau dirumuskan kembali disesuaikan dengan tujuan sasaran dan alternatif baru yang berbeda sebelumnya. ${ }^{8}$

Evaluasi dilakukan dengan tiga langkah antara lain, waktu evaluasi program, bentuk evaluasi program, dan sejauh mana pelaksanaan dan perencanaan tercapai. Meninjau dari analisis data yang diperoleh, meninjau bahwa Madrasah Aliyah Nahdlatul Ulama telah menerapkan 3 langkah evaluasi. Waktu evaluasi program, seperti yang dikatakan kepala madrasah dan guru pada saat wawancara bahwasanya evaluasi ini dilakukan pada setiap minggu untuk tujuannya untuk mengetahui keaktifan siswa dalam mengikuti kegiatan.

Bentuk evaluasi program, seperti yang dikatakan kepala madrasah dan guru pada saat wawancara bahwasanya dalam evaluasi program pendidikana keagamaan dilakukan evaluasi secara menyeluruh terhadap kegiatan yang dilakukan dengan membuat catatan-catatan kecil pada setiap kegiatan, untuk mengetahui kekurangan dari kegiatan yang dilakukan, dan menyempurnakan kegiatan yang perlu disempurnakan.

Sejauh mana pelaksanaan dan perencanaan tercapai, menurut kepala madrasah dan guru pada saat wawancara, antara pelaksanaan dan perencanaan sudah tercapai sejauh ini dengan melakukan evaluasievaluasi terhadap setiap program dan perbaikan-perbaikan yang dilakukan.

\section{KESIMPULAN DAN SARAN}

Berdasarkan hasil penelitian yang dilakukan tentang manajemen program penidikan keagamaan Nahdlatul Ulama (NU) di Madrasah Aliyah Nahdlatul Ulama Lekok pasuruan.

Pertama, Perencanaan Kegiatan program pendidikan keagamaan ini dilaksanakan dengan melihat kebutuhan masa depan, menetapkan tujuan yang berdasarkan pada visi misi madrasah, mempunyai kebijakan masing-masing dari setiap kegiatan, menyusun program, tidak terlalu membutuhkan biaya dan setiap kegiatan mempunyai waktu pelaksanaan masing-masing.

Kedua, Mengidentifikasi jenis tugas dan tanggung jawab dilakukan dengan kemampuan individu, kualifikasi ijazah. Menggolongkan jenis tugas dan tanggung jawab dilakukan dengan melihat waktu dan tempat kegiatan. Menentukan dan mendistribusikan tugas dan tanggung jawab dilakukan dengan melihat jenis kegiatan dan kemampuan di masing- masing bidang.

Ketiga, Pelaksanaan Program Pendidikan Keagamaan NU yaitu pendidikan sholat dhuha berjamaah dan kajian kitab dilaksanakan setiap hari secara berjamaah setelah pembacaan surat al-

\footnotetext{
${ }^{8}$ Dedi Lazwardi, Implementasi Evaluasi Program Pendidikan di Tingkat Sekolah Dasar dan Mengah,Vol.7No.2,(Desember,2017), 155
} 
waqiah. Program pendidikan sholat dhuhur dilaksanakan setiap hari setelah pembacaan surat almulk, asmaul husan sholat dhuhur. Program pendidikan madin dilaksanakan setiap hari setelah KBM selesai yang dikhususkan untuk siswa yang tidak madin dirumahnya. Program pendidikan tahlil dilaksanakan setiap minggu dengan sistem setor hafalan.

Ketiga, Waktu evaluasi dilaksanakan setiap minggu sekali dengan membawa catatancatatan kecil terkait dengan kegiatan yang dilaksanakan. Antara pelaksanaan dan perencanaan sejauh ini sudah mencapai target yang ditentukan.

\section{DAFTAR PUSTAKA}

Fitriani, Laela. 2017, Implementasi Pembelajaran Aswaja (Ahlusunnah wal Jamaah) dan ke-NU an dalam Menanamkan Nilai-nilai keagamaan siswa di Sekolah Dasar Darus Sholah Jeber, Skripsi, Program Guru Madrasah Ibtidaiyah, IAIN Jember.

Hasbullah. 2001, Sejarah Pendidikan Islam, Jakarta: PT Raja Grafindo Persada.

Ibniyanto. 2017, Implementasi Pembelajaran Aswaja Dalam pembentukan Perilaku Sosial dan Keagamaan Peserta Didik di SMA Pesantren Al-In'am Gapura Sumenep, Tesis, Program Pendidikan Agama Islam, Universitas Islam Negeri Sunan Ampel Surabaya.

L.Daft, Richard. 2010, Era Baru Manajemen, Jakarta: Salemba Empat, ed.ke-9.

Lazwardi, Dedi. 2017, Implementasi Evaluasi Program Pendidikan di Tingkat Sekolah Dasar dan Menengah,Jurnal manajemen pendidikan, Vol.7, No.2, Desember.

Madjid Nurcholis. 2010, Masyarakat Religius: membumikan Nilai-nilai Islam Dalam Kehidupan, Jakarta: Dian Rakyat.

Rochman, Fathor. 2015, Manajemen Organisasi dan Pengorganisasian Dalam Perspektif AlQuran dan Hadith, Jurnal Manajemen Pendidikan Islam, Vol.1, No.2, Desember.

Sagala, Syaiful. 2009, Manajemen Strategik dalam Peningkatan Mutu Pendidikan, Bandung: Alfabeta.

St Rodliyah. 2015, Manajemen pendidikan sebuah konsep dan aplikasi, Jember: IAIN JEMBER PRESS.

Sugiono. 2018, Metode Penelitian Kualitatif, Bandung: Alfabeta

Sulisyorini. 2009, Manajemen Pendidikan Islam: Konsep Strategi dan Aplikasi, Yogyakarta:TERAS. 
Yanuarti, Triyas. 2018, Pembelajaran Aswaja Pada Kelas Intensive di SMA Ma'arif Kroya, Skripsi, Program Pendidikan Agama Islam, IAIN Purwokerto. 